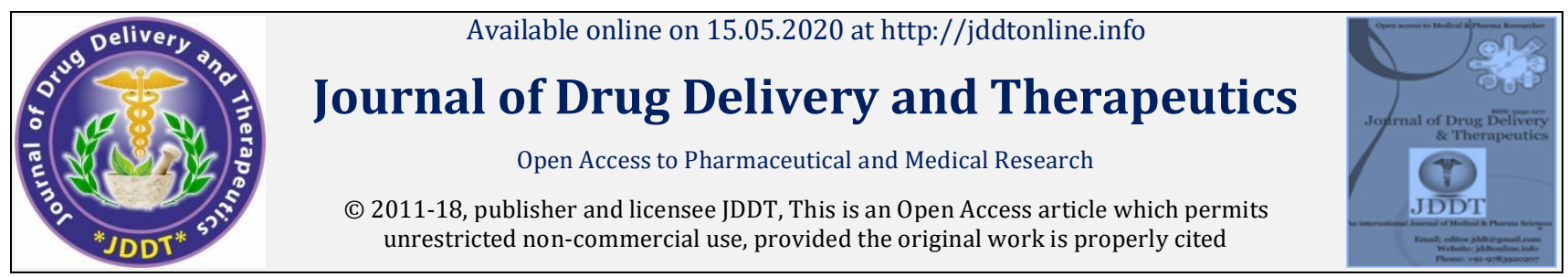

Open Access

Research Article

\title{
Phytochemical, HPLC and FTIR Analysis of Methanolic Extract from Gracilaria dura (C Agardh) J Agardh.
}

\author{
S S Sumayya ${ }^{1}$, A S Lubaina ${ }^{2}$ and K Murugan ${ }^{3 *}$ \\ ${ }^{1}$ Govt. Sanskrit College, Pattambi, Palakkad, Kerala, India \\ ${ }^{2}$ Christian College, Kattakada, India \\ ${ }^{3}$ CISSA, Trivandrum, Kerala, India
}

\begin{abstract}
Marine algae are known to contain a wide variety of bioactive compounds. They are also rich in novel biomolecules and can be explored for the development of drugs to combat lifestyle diseases like cancer, diabetes etc. Red algae are known for their nutraceutical and functional importance. But there are a lot of limitations regarding their availability and in estimating which algal fractions are biologically active. Similarly, the mode of digestion of such compounds in human body is not yet properly traced. In this juncture, the present study was aimed to evaluate the phytochemical screening of the methanolic extract of the red alga, Gracilaria dura. Methanolic extract of $G$. dura showed the presence of reducing sugar, flavonoids, glycosides, tannins and terpenoids. Further, the HPLC analysis was attempted to fractionate the polyphenolics. Various phenolic acids such as of gallic acid, vanillic acid, sinapic acid, p-coumaric acid, hydroxybenzoic, phloroglucinol, catechol and cinnamic acid were identified. Subsequently, the methanolic solvent extract of $G$. dura was subjected to fourier transform infrared spectroscopy for the analysis of the functional groups. The results based on the spectral data of FTIR revealed the presence of aliphatic constituents containing alkanes, ketones, alkyl halides, hydroxyl groups etc. Thus, the observed finding envisages that methanolic extract of $G$. dura contained potential bioactive compounds which can be used for analysing the various biological activities.
\end{abstract}

Keywords: Gracilaria dura, Phytochemical, Methanolic extract, HPLC, FTIR

Article Info: Received 08 March 2020; Review Completed 21 April 2020; Accepted 28 April 2020; Available online 15 May 2020

Cite this article as:

Sumayya SS, Lubaina AS, Murugan K, Phytochemical, HPLC and FTIR Analysis of Methanolic Extract from Gracilaria dura (C Agardh) J Agardh. , Journal of Drug Delivery and Therapeutics. 2020; 10(3):114-118 http://dx.doi.org/10.22270/jddt.v10i3.3996

*Address for Correspondence: Dr. Murugan K, Director, CISSA, Trivandrum, Kerala, India

\section{INTRODUCTION}

The marine ecosystem is a unique source of bioactive natural products, many of which exhibit structural features not found in terrestrial natural products. Seaweeds also have the valuable medicinal components such as antibiotics, laxatives, anticoagulants, antiulcer products and suspending agents in radiological preparations. Fresh and dry seaweeds are extensively consumed by native people especially living in the coastal areas. From the literature, it is observed that the edible seaweeds contains significant amount of the protein, vitamins and minerals essential for the human nutrition 1 . Seaweeds contain pool of secondary metabolites such as alkaloids, glycosides, flavonoids, saponins, tannins, steroids which have been extensively used in the drug and pharmaceutical industries ${ }^{2}$. The demand of marine organisms as a potential and a promising source of pharmaceutical agents has increased during recent years. Numerous pharmacological studies on marine algae have reported that the chemical compounds produced from them had a wide range of biological activities such as anti- inflammatory, anticancer, anti-HIV, antimutagenic and scavenging free radicals ${ }^{3,4}$. Bioactive rich marine seaweeds could potentially be exploited as functional ingredients for both human and animal health applications. Seaweeds are rich in antioxidant such as carotenoids, pigments, polyphenols, enzymes and diverse functional polysaccharide 5 . Phytochemicals are the markers for medicinal potentiality of plants. These are non-nutritive chemicals that have protected human beings from various diseases. So, phytochemical analysis of the seaweeds will be an ideal basic approach to further isolation and purification of secondary metabolite constituents and evaluation of their medicinal values. For centuries, many of the seaweed secondary metabolites have been used in traditional medicines due to their documented therapeutic potentials 6 . The components reported previously were sterols (some are fucosterol), different molecules containing vinyl and ethyl cholesterol types, cyclohexane and some sulfated polysaccharides fucoidan, neutral glucan and guluronic and mannuronic acid residues containing alginic acid with 
pharmaceutical and cosmetic values ${ }^{7}$. Recent studies on marine macroalgae have contributed to the isolation and chemical determination of several compounds, including fatty acids, sterols, phenolic compounds, terpenes, enzymes, polysaccharides, alkaloids, and flavonoids. Phenolic compounds are commonly found in edible brown, green and red seaweeds, whose antioxidant properties have been correlated with their type of phenolic contents ${ }^{8}$. The presence of these secondary metabolites in seaweeds is highly evident of their resultant pharmaceutical potentials. Recently, Francavilla et al. ${ }^{9}$ found that Gracilaria species harvested may be used as an alternative source of natural porous material with several biotechnological applications. Gracilaria species were used as food stuff in Japan, Hawai and Philippines. In recent years, it is getting more and more consideration, not only owing to its food value, but also for the progress of research of its potential pharmaceuticals. Further, Budarin et al.,10 found that microwave induced pyrolysis of this macroalga produced chemical rich bio-oils which are rich in aromatics, sugars and other high value chemicals. There were several reports on antimicrobial and pharmacological activities of different solvent extracts from marine algae ${ }^{11,12}$. But no reports are available on intensive phytochemical studies using HPLC and FTIR studies on the marine seaweed $G$. dura. In this line, the present study was aimed to evaluate the phytochemicals, RP-HPLC analysis of phenolic acids, FT-IR analysis of methanolic extracts of the red seaweed Gracilaria dura.

\section{MATERIALS AND METHODS}

\subsection{Sample collection and preparation}

The marine algae Gracilaria dura was collected during June 2017, from the Mandapam coast (latitude $9^{\circ} 17^{\prime} \mathrm{N}$ longitude $79^{\circ} 22^{\prime} \mathrm{E}$ ), Gulf of Mannar. The thalli were then cut into pieces, shade dried and powdered in a grinder to 40 mesh size powder. The ground samples were then kept in air-tight container and stored until for further analysis. The extraction was done by soxhlet apparatus (Methanol as solvent). The extracts was evaporated to total dryness by vacuum distillation and preserved in refrigerated condition for further analysis.

\subsection{Preliminary Phytochemical Analysis}

Phytochemical analysis was performed according to the standard protocol of Balachandran et al ${ }^{13}$. The prepared seaweed extract were subjected to preliminary phytochemical screening for the presence of reducing sugar, flavinoids, glycosides, lignin, saponins, steroids, tannins and terpenoids.

\subsection{Determination of total carbohydrate}

$1 \mathrm{ml}$ of the sample was added to $5 \mathrm{~mL}$ of $2.5 \mathrm{~N} \mathrm{HCl}$ for $3 \mathrm{~h}$. It was neutralized with sodium carbonate and centrifuged. 4 $\mathrm{mL}$ of anthrone reagent was added. The absorbance was recorded at $630 \mathrm{~nm}$.

\subsection{Determination of protein}

The amount of protein present in the algal extract was calculated spectrophotometrically at $670 \mathrm{~nm}$ after $30 \mathrm{~min}$ using appropriate blank ${ }^{14}$.

\subsection{Determination of total phenolic content}

The amount of total phenolics in the seaweed was determined with the Folin-Ciocalteau reagent. Gallic acid was used as standard and the total phenol were expressed as $\mathrm{mg} / \mathrm{g}$ gallic acid equivalents (GAE). The blue colour was measured spectrophotometrically at $765 \mathrm{~nm}$ and expressed as $\mathrm{mg} \mathrm{GAE} / \mathrm{g}$ of the sample.

\subsection{HPLC analysis}

HPLC method was performed on Shimadzu LC-10 AT VP HPLC system, equipped with LC-10AT pump, UV-VIS detector an auto injector SIL-10AT. A Hypersil -BDS C-18 column with $\mathrm{C}-18$ guard column was used. An isocratic HPLC with wo LC-10 AT VP pumps (Shimadzu), variable wave length programmable photo diode array detector SPD-M10A VP, CT0-10AS VP column oven (Shimadzu), SCL-10A VP system controller (Shimadzu) and reverse phase Luna5-C18 (2) column $250 \mathrm{~mm} \times 4.6 \mathrm{~mm}$ was used. The mobile phase consists of Potassium hydrogen phosphate and acetonitrile in a ratio of 75:25 at a flow rate of $1 \mathrm{ml} / \mathrm{min}$ which yielded a column backup pressure of $260-270 \mathrm{kgf} / \mathrm{cm}^{2}$. The column temperature was maintained at $27{ }^{\circ} \mathrm{C} .20 \mathrm{ml}$ of the respective sample was injected using Rheodyne syringe. The elution was carried out with gradient solvent systems with a flow rate of $1 \mathrm{ml} / \mathrm{min}$ at an ambient temperature (25-28 ${ }^{\circ} \mathrm{C}$ ). The sample injection volume was $20 \mu \mathrm{l}$ whilst the wavelength of the UV-VIS detector was set at $254 \mathrm{~nm}$.

\subsection{FT-IR analysis}

The FT-IR studies have been followed as per the method described by Diem ${ }^{15}$. Dried powder of different solvent extracts of algae was used for FTIR analysis. $10 \mathrm{mg}$ of the dried extract powder was encapsulated in $100 \mathrm{mg}$ of $\mathrm{KBr}$ pellet. IR spectra region between 4000-400 cm-1 were recorded at room temperature on a perkin Elmer fourier transform spectrometer equipped an air cooled DTGs (deuterated triglycine sulfate) detector The frequencies for all sharp bands were accurate to $0.01 \mathrm{~cm}^{-1}$.

\section{RESULT AND DISCUSSION}

Phytochemicals like polyphenolic groups such as flavonoids, terpenoids were growing interest because of their potent antioxidant potentiality ${ }^{16}$. The phytochemicals noticed in the red algae are known for their anti-inflammatory, antidiabetic and analgesic activities and also supportive of central nervous system activity. Qualitative analysis of methanolic extract of $G$. dura shows the presence of reducing sugar, flavonoids, glycosides, tannins and terpenoids. Interestingly, the terpenoids was present in remarkable levels (Table 1).

Table 1: Qualitative analysis of phytochemicals from the methanolic solvent extract of $G$. dura

\begin{tabular}{|l|c|}
\hline & Methanolic extract \\
\hline Reducing sugar & ++ \\
\hline Flavonoids & ++ \\
\hline Glycosides & + \\
\hline Lignin & - \\
\hline Saponins & - \\
\hline Steroids & + \\
\hline Tannins & +++ \\
\hline Terpenoids & - \\
\hline \multicolumn{1}{|c|}{$++=$ abundant, $++=$ moderate,$+=$ low,$-=$ absent }
\end{tabular}

The importance of alkaloids, phenols and glycosides as microbicidal against common pathogenic strains has been reported by Sharma et al ${ }^{17}$. Terpenoids from seaweeds displayed wide spectrum of activities such as cytotoxic, nematicidal and anti-tumour. Seaweeds have afforded to date the highest number of compounds having various biological activities within a single group of organisms. Among the red algal metabolites, dehydrothyrsiferol a triterpenoid polyether isolated from Laurencia viridis has exhibited promising cytotoxic activity. They show cytotoxic 
effect against human estrogen receptor of breast cancer cell lines ${ }^{18}$.

Carbohydrate content forms the major component in G. dura (dry weight basis) i.e., $110 \mathrm{mg} / \mathrm{g}$ DW. The protein content was $221 \mathrm{mg} / \mathrm{g}$ DW. The obtained results were almost similar to previous reports in other sea weeds i.e., carbohydrate and protein content was comparable to other green and red seaweeds ${ }^{16}$. In addition, the phytochemical screening also showed the presence of phenols in substantial amount i.e., $1.305 \pm 0.03 \mathrm{mg}$ gallic acid equivalent / g dry seaweed. Previous studies reported that the total phenolic contents among the green, brown and red seaweeds displayed much variation. The green seaweeds have higher free-radical scavenging properties, followed by the red and brown seaweeds ${ }^{19}$.

Further, the HPLC analysis was carried out to fractionate polyphenolics components present in the extract. The C18 column was used to fractionate the polyphenolic contents. From the Fig. 1, it can be interpreted that a good separation was achieved within a short period of time. For the polyphenolic standards various symmetrical, sharp and well-resolved peaks were observed. The elution order and the quantified volume of gallic, vanillic, sinapic, p-coumaric, hydroxybenzoic, phloroglucinol, catechol and cinnamic acid were $339.01,722.34,632.05,84.61,163.57,184.32,82.99$ and $435.22 \mu \mathrm{g} / \mathrm{g}$ respectively (Table:2, Fig.1). Vanillic acid was found to be in higher level followed by sinapic acid, whereas coumaric acid and catechol were the lowest. Phenolic acids proved their beneficial effects in terms of antioxidant, anti-ageing and protect cardiovascular issues. Further, they help to reduce oxidative stress, lipid peroxidation, free radical generation and cholesteroloxidation of low density lipoprotein (LDL) content ${ }^{16}$.

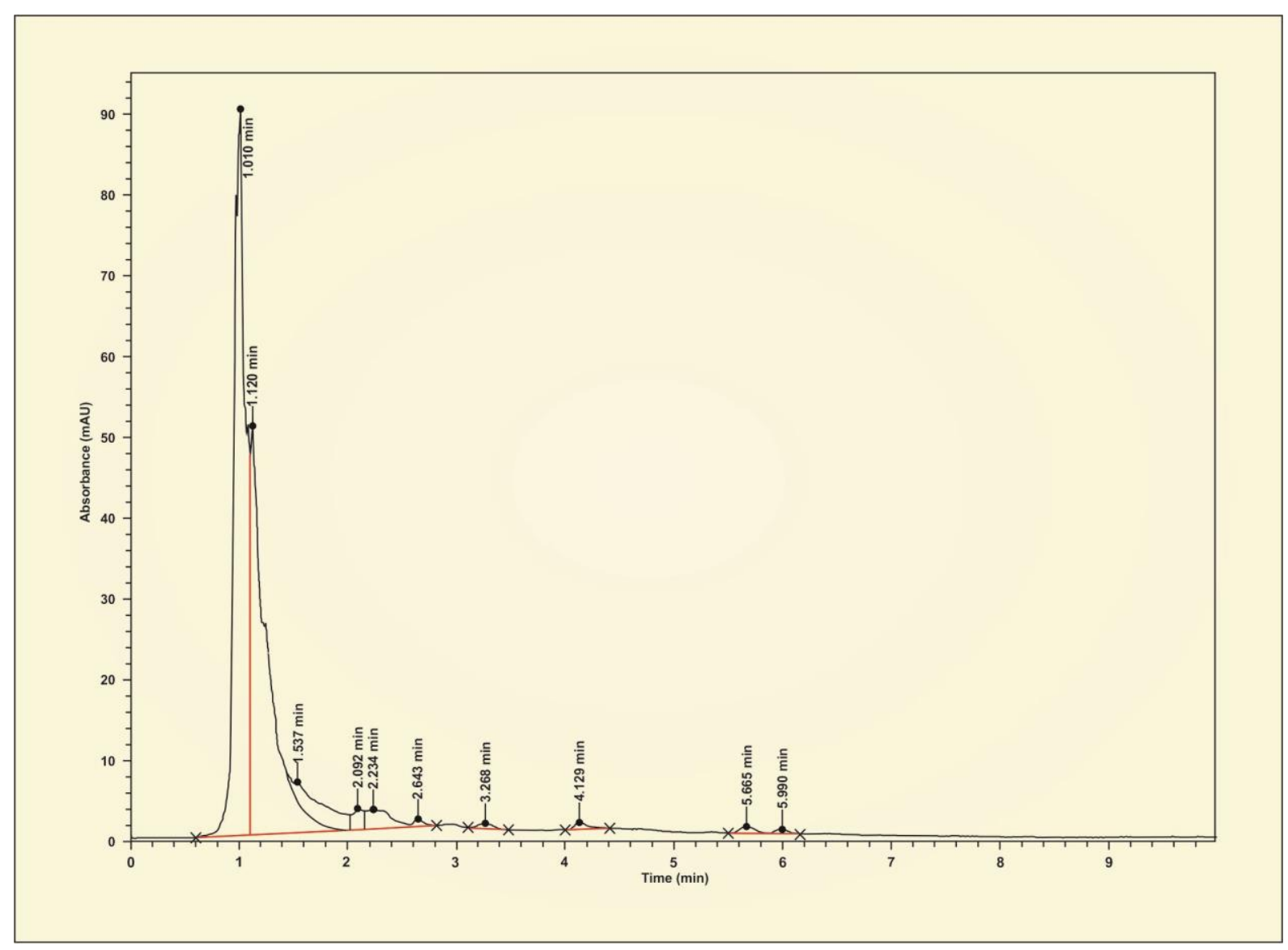

Figure 1: HPLC chromatogram of methanolic extract of $G$. dura

Table 2: RP-HPLC profile of phenolic compounds in G. dura

\begin{tabular}{ll}
\hline Compound & Concentrations $(\boldsymbol{\mu g} / \mathbf{g})$ \\
\hline Gallic acid & 339.01 \\
\hline Vanillic acid & 722.34 \\
\hline Sinapic acid & 632.05 \\
\hline p-coumaric & 84.61 \\
\hline Hydroxybenzoic & 163.57 \\
\hline Phloroglucinol & 184.32 \\
\hline Catechol & 82.99 \\
\hline Cinnamic acid & 435.22 \\
\hline
\end{tabular}


Phenolic compounds are found remarkably high in medicinal plants. They were also present in seaweeds, and have been reported to have wide range of biological activities including antioxidant 20 . The HPLC analysis of Gracilaria corticata and Spirulina platensis was correlated with the bioactive compounds vs antioxidant activity. The HPLC analysis of the algae Amphiroa anceps revealed that the polyphenolic compounds present in them were an effective source of antioxidants. Therefore, the seaweed extracts may have potential applications in the food industries. Nagai and Yukimoto, also reported that the phenolic compounds are one of the most effective antioxidants ${ }^{21}$.

The FTIR analysis of the methanolic extract of $G$. dura confirmed the presence of amines $1^{0} \& 2^{0}$, alkenes, alkanes aldehydes, ketones, carboxylic acids, aromatic amines, alkylhalides, aliphatic amines, terpenoids, anthraquiniones (Fig:2; Table: 3).

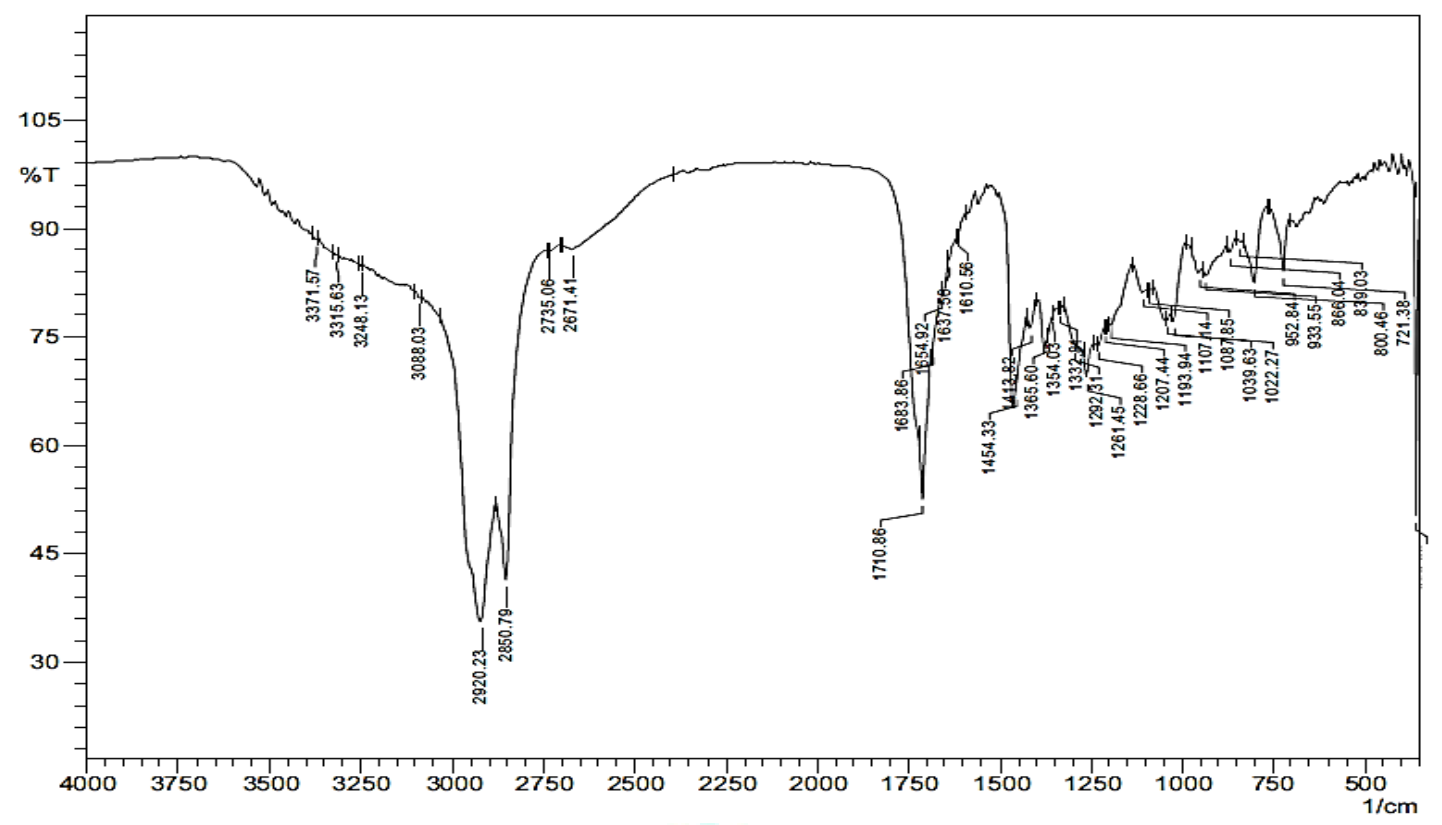

Figure 2: FTIR spectrum of methanolic extract of $G$. dura

Table 3: FT-IR profile of functional groups (cm-1) in methanolic extract of $G$. dura

\begin{tabular}{|l|l|l|}
\hline Functional groups & Peaks & Bond \\
\hline Amines & $3371.57,3315.63,3248.13,1637.56,1610.56$ & N-H stretch \\
$10 \& 20$ amines & $952.84,935.55,866.04,839.03$ & N-H bend,N-H wag \\
\hline Alkanes & $2920.23,2850.791365 .60,1354.03,721.38$ & C-H Stretch,C-H rock \\
& 1462.04 & H-C-H bend \\
\hline Alkenes & $3088.03,1610.56,1637.56,1654.92$ & C=C-H , C=C-C symmetric stretch \\
\hline Aldehydes & $2850.79,2735.06$, & C-H Stretch of C=O \\
& $1710.86,1683.68,1654.92,1637.56$ & C=O Stretch \\
\hline Ketones & $1654.92,1683.68,1710.86$ & C=O Stretch \\
\hline Carboxylic acids & $2735.06,2671.41$ & H bonded OH stretch \\
& $1710.86,1683.68,1654.92,935.55$ & C=O stretch, OH bend \\
\hline Aromatic amines & $1332.81,1292.31,1261.45$ & C-N stretch \\
\hline Alkyl halides & $1228.66,1207.44,1193.94$ & C-H wag \\
\hline Alipatic amines & $866.04,839.03,800.46,721.38$ & C-Cl stretch \\
\hline Terpenoids & $1107.14,1087.85,1039.63,1022.27$ & C-N stretch \\
\hline Anthraquinones & 12650.79 & C=O stretch \\
\hline
\end{tabular}

Similar findings were documented in brown algae like Sargassum wightii. Thus, the obtained data of G. dura corroborates with $S$. wightii 22 . Currently, FTIR spectroscopy become more popular developed method due to its ease of sample preparation and requires little samples size, and does not require the use of solvents. Most FTIR studies on the extracts of seaweeds revealed the interaction of toxic sites such as carboxyl, amino acid and hydroxyl groups. Like other biological molecules, algae show complex vibrational spectra in all bands. But metal legend stretching frequencies and properties of functional groups coordinated with be toxic centres that provide useful information. $\mathrm{C}-\mathrm{O}$ stretching, $\mathrm{NH}_{2}$ rocking, $\mathrm{C}-\mathrm{O}$ and $\mathrm{CH}_{2}$ stretching bands are metal sensitive and are shifted as the metal is changed, but $\mathrm{NH}_{2}$ vibrations are very sensitive to the intermolecular interactions and its effect makes it difficult to discuss the strength of the metalnitrogen bond from the frequency shift 23 . Similar FTIR studies on the fresh water algae Spirulina powder also confirmed the presence of several functional groups that causes improvement of the health status and in normalizing 
the atrazine toxicity 23,24 . The results of the FTIR spectrum confirmed the polyphenols and are potential antioxidants. Free radical scavenging effect of Morinda citrifolia fruit extract was correlated with the functional groups 25 . The presence of the bioactive compounds in the plant is significant for their medicinal properties. Phenol and other organic constituents in Spilanthus acmella which is an acutely threatened medicinal plant was also revealed by the FTIR data ${ }^{26}$. Numerous studies have showed that there are many research utilizing the FTIR for the analysis of bioactive compounds. These include research in food technology, pharmaceutical and medicinal. For example, the medicinal herb, Clitoria ternatae, revealed the presence of bioactive compounds such as alcohols, phenols, primary, secondary amines, carboxylic acids and nitro compounds and was validated by the FTIR spectra ${ }^{27}$. These phytochemicals noticed in leaves and flowers of this plant can be utilized as an alternative source of natural antioxidants.

\section{CONCLUSION}

The phytochemical investigation suggest that the marine red alga $G$. dura contains important phytochemicals like reducing sugar, flavonoids, glycosides, tannins and terpenoid, which may contribute to its biological activities. The present results clearly indicate that $G$. dura methanolic extract possess significant phenolic acids and therefore capable of antioxidant activities like synthetic drug ascorbate. FT-IR spectroscopy of the methanolic solvent extract of $G$. dura reveals diverse functional groups and there by confirmed the possible potential antioxidant activity and free radical scavenging properties. Future perspectives include isolation, purification of lead molecule and to justify its biological potentialities.

\section{CONFLICT OF INTEREST}

The authors declare that they have no conflict of interest.

\section{REFERENCES}

1. Fayaz M, Namitha KK, Murthy KNC, Swamy MM, Sarada R, Khanam S, Subbarao PV, Ravishankar GA, "Chemical composition, iron bioavailability, and antioxidant activity of Kappaphycus alvarezzi (Doty)" Journal of Agricultural and Food Chemistry, 2005; 53(2):792-797.

2. Eluvakkal T, Sivakuamr SR, Arunkumar K, "Fucoidan In Some Indian Brown Seaweeds Found Along The Coast Of Gulf of Mannar" International Journal of Botany, 2010; 6(2):176-181.

3. Cornish ML, Garbary DJ, "Antioxidants From Macroalgae: Potential Applications In Human Health And Nutrition" Algae, 2010; 25(4):155-171.

4. Bechelli JM, Coppage K, Rosell J, Liesveld, “Cytotoxicity of algae extracts on normal and malignant cells" Leukemia Research and Treatment, 2011; 5(1):1-7.

5. Vinayak RC, Sabu AS, Chatterji A, "Bio-prospecting of a few brown seaweeds for their cytotoxic and antioxidant activities" Evidence Based Complementary and Alternative Medicine, 2011; 7(2):1-9.

6. Brownlee A, Fairclough AC, Hall AC, Paxman JR, "The potential health benefits of seaweed and seaweed extracts" Nova Science Publishers, 2012; 4(1):119-136.

7. Ibanez E, Herrero M, Mendiola JA, Castro-Puyana MM, "Extraction and Characterization of Bioactive Compounds With Health Benefits From Marine Resources: Macro And Micro Algae, Cyanobacteria And Invertebrates, in Marine Bioactive Compounds Sources, Characterization and Applications" $2^{\text {nd }}$ ed. New York, Springer; 2012. p.55 - 98.

8. Ganesan PC, Kumar S, Bhaskar N, "Antioxidant properties of methanol extract and its solvent fractions obtained from selected Indian red seaweeds" Bioresource Technology, 2008; 99(8):2717- 23.

9. Francavilla M, Pineda A, Lin CSK, Franchi M, Trotta P,
Romero AA, Luque R, "Natural Porous Agar Materials From Macroalgae" Carbohydrate Polymer, 2013; 11(10):15551560.

10. Budarin VL, Zhao Y, Gronnow MJ, Shuttleworth PS, Breeden SW, Macquarrie DJ, Clark JH, "Microwave-Mediated Pyrolysis of Macro-Algae" Green Chemistry, 2011; 9(4):2330-2333.

11. Seenivasan R, Rekha M, Geetha S, "Antibacterial Activity and Phytochemical Analysis of Selected Seaweeds from Mandapam Coast, India" Journal of Applied Pharmaceutical Science, 2012; 2(10):159-169.

12. A1-Saif SS, Adbel-Raouf N, E1-Wazanani HA, Aref IA, "Antibacterial Substances From Marine Algae Isolated From Jeddah Coast Of Red Sea, Saudi Arabia" Saudi Journal of Biology and Science, 2013; 21(1):57-64.

13. Balachandran P, Anson MS, Ajay K, Parthasarathy V, "Preliminary phytochemical analysis of the ethanolic extract of brown Seaweed Sargassum wightii" International Journal of Research in Pharmaceutical Sciences, 2016; 7(2):154-156.

14. Barbarino E, Lourenço SO, "An evaluation of methods for extraction and quantification of protein from marine macroand microalgae" Journal of Applied Phycology, 2005; 17:447460.

15. Diem M, Romeo M, Boydston-White S, Miljkovic M, Matthaus C, "A Decade Of Vibrational Micro-Spectroscopy Of Human Cells And Tissue (1994-2004)" Analyst, 2004; 129(10):880-885

16. Matanjun P, Mohamed S, Mustapha NM, Muhammad K, Ming $\mathrm{CH}$, "Antioxidant Activities And Phenolics Content Of Eight Species Of Seaweeds From North Borneo". Journal of Applied Phycology, 2008; 20(4):367-373.

17. Sharma C, Sharma A, Katoch M, "Comparative Evaluation of Antimicrobial Activity of Methanolic Extract And Phenolic Compounds Of A Liverwort, Reboulia hemispherica" Archive for bryology, 2013; 4(1):192-201.

18. Souza BW, Cerqueira MA, Martins JT, Quintas MA, Ferreira AC Teixeira JA, Vicente AA, "Antioxidant potential of two red seaweeds from the Brazilian coasts" Journal of Agriculture and Food Chemistry, 2011; 59(10):5589-5594.

19. Duan XJ, Zhang WW, Li, XM, Wang BG, "Evaluation of Antioxidant Property Of Extract And Fractions Obtained From Red Algae, Polysiphonia urceolata" Food Chemistry, 2004; 95(2):37-43.

20. Kuda T, Kunii T, Goto H, Suzuki T, Yano T, "Varieties Of Antioxidant And Antibacterial Properties of Ecklonia stolonifera and Ecklonia kurome Products Harvested And Processed In The Noto Peninsula, Japan" Food Chemistry, 2007; 103(3):900-905.

21. Nagai T, Yukimoto T, "Preparation and Functional Properties Of Beverages From Sea Algae" Food Chemistry, 2003; 81:32732.

22. Marimuthu J, Essakimutju P, Narayanan J, Antham B, Tharamaraj RJJM, Arumugam S, "Phytochemical Characterization of Brown Seaweed Sargassum wightii" Asian Pacific Journal of Tropical disease, 2012; 82(3):109- 13.

23. Doshi H, Ray A, Kothari IL, "Bioremediation Potential of Live And Dead Spirulina: Spectroscopic, Kinetics And SEM Studies" Biotech and Bioengineering, 2007; 96(6):1051-1063.

24. Venkatesan S, Pugazhendy K, Sangeetha D, Vasantharaja C, Prabakaran S, Meenambal M "Fourier Transform Infrared (FTIR) Spectoroscopic Analysis of Spirulina" International Journal of Pharm and Biological Science Archive, 2012; 3(4):969-72.

25. Vennila $S$ \& Brindha D. "Antioxidant and free radical scavenging effect of Morinda citrifolia fruit extract". International Journal of Pharmacy and Pharmaceutical Sciences, 2014; 6:55-59.

26. Preetha TS, Mohan SN, Deepthi SR, “Chemical Fingerprinting of Spilanthes acmella L.(Murr.) - An Acutely Threatened Medicinal Plant of Pharmaceutical Importance by HPLC, FTIR and UV-VIS Spectroscopic Tools" World Journal of Pharmcy and Pharmaceutical Science, 2014; 3(2):1275-1287.

27. Lakshmi CM, Raju BP, Madhavi T, Sushma, NJ, "Identification of Bioactive Compounds By FTIR Analysis And In Vitro Antioxidant Activity of Clitoria ternatea Leaf And Flower Extracts" Indo American Journal of Pharmacy and Research, 2014; 4(9):3894-3903. 